\title{
QUALIDADE DE VIDA E BEM-ESTAR NO TRABALHO: AUTOPERCEPÇÃO DOS SERVIDORES DE UMA UNIVERSIDADE FEDERAL
}

\author{
R. P. V. LOPES, L. R. R. G. MADRUGA, L. V. AVILA , T. A. BEURON \\ Universidade Federal de Santa Maria - UFSM \\ Lucas.avila@ufsm.br*
}

Submetido 21/09/2016 - Aceito 28/10/2018

DOI: $10.15628 /$ holos.2018.6217

\section{RESUMO}

O presente estudo tem como objetivo identificar a auto percepção dos servidores da Universidade Federal de Santa Maria, quanto ao seu bem-estar no trabalho; e ainda, sugerir atividades com abordagens multidisciplinares visando a melhoria da qualidade de vida e o bem-estar no trabalho dos servidores. Para a realização deste estudo, optou-se por um levantamento em uma das subunidades acadêmicas, Centro de Artes e Letras (CAL), que possui 43 Servidores TécnicoAdministrativos, alocados em níveis de apoio, intermediário e superior e com cargos administrativos e técnicos de nível de área afim, sobre qualidade de vida e bem-estar no trabalho. Quanto à abordagem de pesquisa, classifica-se como uma pesquisa qualitativa e quantitativa. A coleta de dados foi realizada por meio de instrumento elaborado com base no questionário desenvolvido e validado por Constantino (2007). Os principais achados revelam que os Servidores estão satisfeitos foi possível perceber que o Servidor TAE apresenta satisfação com sua qualidade de vida, o fator mais insatisfatório foi relacionado com atividades físicas o que suscitou a sugestão acerca da ginástica laboral.

PALAVRAS-CHAVE: Qualidade de Vida no Trabalho, Bem-estar no Trabalho.

\section{QUALITY OF LIFE AND HEALTH AT WORK: PERCEPTION SERVERS FROM A FEDERAL UNIVERSITY}

\begin{abstract}
This study aims to identify the self-perception of the servers Federal University of Santa Maria, about their well-being at work; and also suggest activities with multidisciplinary approaches aimed at improving the quality of life and well-being at work the servers. For this study, we opted for a survey in one of the academic subunits, Arts and Letters Centre (CAL), which has 43 technical and administrative staff, allocated in support levels, intermediate and upper and administrative positions and technical area level in order, on quality of
\end{abstract}

life and well-being at work. As for the research approach is classified as a qualitative and quantitative research. Data collection was carried out through an instrument designed based on a questionnaire developed and validated by Constantine (2007). The main findings reveal that the servers are satisfied it was revealed that the TAE Server presents satisfaction with their quality of life, the most unsatisfying factor was related to physical activities which raised the suggestion about gymnastics.

KEYWORDS: Quality of Life at Work, Welfare at Work. 


\section{INTRODUÇÃO}

A Qualidade de Vida é uma questão muito importante para todas as pessoas e um objetivo a ser alcançado em qualquer estágio ou circunstância da vida. Quando relacionada ao trabalho passa pela necessidade de que este reproduza ambientes que proporcionem às pessoas melhores condições de bem-estar. Alcançar qualidade de vida, tanto no cotidiano quanto no trabalho, é um esforço que envolve o compromisso de cada um, buscando atender às necessidades biopsicossoais, e exige também um comprometimento das organizações em proporcionar condições favoráveis para que o trabalhador se sinta confortável no ambiente de trabalho.

Inserida nesse contexto, este artigo apresenta os resultados de pesquisa, onde foi verificada, a auto percepção dos servidores técnico-administrativos em Educação (TAE) do Centro de Artes e Letras (CAL) de uma Universidade Federal quanto à Qualidade de Vida e ao Bem-Estar no Trabalho. A realização de um diagnóstico da qualidade de vida dos servidores e a implementação de atividades preventivas buscando melhorar as condições funcionais e pessoais, são essenciais na busca de um ambiente adequado.

O comportamento dos servidores, tanto na vida privada quanto no ambiente funcional, é determinante no processo de avaliação da qualidade de vida. Observando-se o dia a dia dos servidores no local de trabalho constata-se, de forma empírica, que existem fumantes; pessoas com carências afetivas e dificuldades em seus relacionamentos afetivos, familiares e sociais; pessoas que não praticam esportes com regularidade, indicando a existência de sedentarismo e outras questões relacionadas com a sua qualidade de vida.

Somam-se a isto às exigências do trabalho, com a imposição cada vez mais acirrada de obtenção de resultados em curto prazo, o que causa desconforto aos servidores e com isso, muitas vezes pode levar ao consumo excessivo de energia, que junto aos problemas familiares deixa os colaboradores vulneráveis a situações causadoras de estresse.

Nesse contexto, os servidores, não raras vezes, são acometidos por processos depressivos e adoecem, comprometendo a capacidade de desempenho físico e intelectual. Esse quadro pode ser revertido pela implementação de práticas que busquem, de modo preventivo, a qualidade de vida no trabalho. Para tanto, existem recursos como: prática de esportes, grupos de encontros, trabalhos comunitários, práticas de religiões, participação em clubes sociais, danças e muitas outras atividades. Os cuidados com a saúde aumentam a longevidade e melhoram a qualidade de vida. A vida sedentária e a falta de cuidados com a alimentação causam problemas de saúde como diabetes, doenças cardiovasculares, obesidade, tendência ao estresse e, também, depressão.

De acordo com Limongi-França e Rodrigues (2013), QVT é um conceito amplo e comprometido com as condições de vida no trabalho, que inclui aspectos de bem-estar, garantia da saúde e segurança física, mental e social e capacitação para realizar tarefas com segurança. Alinhado a esse conceito, essa pesquisa busca identificar a auto percepção dos servidores quanto ao bem-estar no trabalho; e propor atividades com abordagens multidisciplinares tendo em vista a melhoria da qualidade de vida e o bem-estar no trabalho dos servidores. 


\section{BEM- ESTAR NO TRABALHO (QVT)}

A Qualidade de Vida no Trabalho (QVT) não possui um conceito definido e plenamente aceito. É um tema abrangente e, geralmente, confuso. Suas definições vão desde cuidados médicos estabelecidos pela legislação de saúde e segurança até atividades de integração e lazer. A maioria das compreensões em QVT consideram as condições de vida e do bem-estar de pessoas, grupos, comunidades e até mesmo do planeta inteiro e de sua inserção no universo.

De acordo com Limongi-França e Rodrigues (2013), QVT é um conceito amplo e comprometido com as condições de vida no trabalho, que inclui aspectos de bem-estar, garantia da saúde e segurança física, mental e social e capacitação para realizar tarefas com segurança.

Atentando-se ao conjunto e à natureza das questões a respeito do tema e dos diversos conceitos, critérios e abordagens, Limongi-França (2012) agrupou as dimensões sob as quais o tema é abordado em três escolas de pensamento: socioeconômica, organizacional e condição humana no trabalho. A Escola Socioeconômica, considerada uma terceira via, ressalta os efeitos da globalização e da tecnologia sobre o ambiente de trabalho e está fundamentada na igualdade social, na proteção aos vulneráveis, na liberdade com autonomia, nos direitos com responsabilidade, na autoridade com democracia, no pluralismo cosmopolita, entre outros, tendo como princípios básicos: o desenvolvimento da cidadania; a responsabilidade e projetos sociais; a igualdade com liberdade; a preservação do meio ambiente; e o desenvolvimento sustentável.

Segundo Limongi-França (2012) a Escola Organizacional, centra-se na crença de que a QVT envolve uma dimensão especifica do local onde as relações de produção acontecem, pois grande parte das relações de trabalho, de suas práticas e seus valores surge de experiências no chão de fábrica, dos processos de controle da produção, dos tempos e movimentos, evoluindo para qualidade total e critérios de excelência, destacando-se como: a expansão dos processos de qualidade e produtividade para o de qualidade pessoal; a política de gestão de pessoas, valorização e capacitação; o marketing, a imagem corporativa e comunicação interna; o tempo livre, o desenvolvimento cultural, hábitos de lazer e esporte; e o risco e desafio como fatores de motivação e comprometimento.

Albuquerque e Limongi-França (1998) sustentam que QVT envolve diagnóstico e implantação de ações de melhorias e inovações gerenciais, tecnológicas e estruturais, dentro e fora do ambiente de trabalho, com o objetivo de proporcionar condições adequadas para o desenvolvimento e realização das tarefas.

Rossi; Quick e Perrewé (2009) entendem QVT como consequência de ações macro e micro dimensionados, intra e extra institucionais, que ajustam as práticas organizacionais com as características e necessidades pessoais e profissionais e com a realidade do processo e das relações de trabalho. Para eles, a complexidade do conceito surge quando se analisa a multiplicidade de fatores que afetam o ambiente, a organização, o trabalhador, o processo e as relações de trabalho, que se modificam no tempo e nos cenários.

Ao longo das várias fases da civilização humana, o trabalho era atividade dos servos e dos escravos, e que, na era moderna, esse entendimento está associado a emprego. Assim, as organizações que pretendem desenvolver a empregabilidade de seus membros precisam levar 
em conta a necessidade de trabalho das pessoas numa perspectiva de ocupação humana (WOLECK, 2000).

A Gestão da Qualidade de Vida no Trabalho (GQVT) consiste no conjunto de critérios de bem-estar que buscam o equilíbrio Biológico, Psicológico, Social e Organizacional (BPSO), a partir do vínculo com o trabalho. Marras (2009) cita as seguintes associações entre as ações e os domínios BPSO: hábitos saudáveis associam-se à dimensão Biológica; autoestima e reconhecimento, à dimensão Psicológica; consumo e educação, à dimensão Social; e ergonomia e clima, à dimensão Organizacional.

No tema QVT é fundamental considerar o ambiente de trabalho. Muitas organizações têm demonstrado interesse pelo tema QVT, a fim de melhorar o desempenho de seus colaboradores tanto nos níveis profissional como pessoal. Neste sentido as empresas, em sua maioria do setor privado, implementam programas de QVT. Já o setor público não evidencia o mesmo interesse por essas políticas. Com base nessa perspectiva Amorim (2010) desenvolveu uma pesquisa sobre a qualidade de vida do servidor público do Ministério Público do Estado de Pernambuco (MPPE) cujo objetivo era avaliar o nível de qualidade de vida desses no exercício de suas atividades profissionais, relacionando-os com os principais aspectos da QVT. Os funcionários demonstraram-se satisfeitos quanto ao nível de QVT da instituição, no que se refere a condições e instrumentos de trabalho, jornada de trabalho, remuneração e natureza do trabalho realizado, embora a instituição não apresente um programa estruturado nesse sentido (AMORIM, 2010).

Desde a década de 1970 salários equânimes, segurança no emprego, fatores motivacionais, realização e a participação nas decisões de seu próprio trabalho, são pontos centrais para estudos de QVT. Segundo Westley (1979) pode-se relacionar problemas enfrentados por funcionários com o desempenho de suas funções, por exemplo: problemas políticos ocasionam insegurança no emprego, dificuldades econômicas resultam, por vezes, em injustiças, distúrbios psicológicos podem levar a alienação e conflitos sociológicos à falta de envolvimento no trabalho.

Segundo Limongi- França et al (2013) a educação tecnológica auxilia na formação de uma grande parcela de trabalhadores qualificando-os para atuar em um mercado de trabalho competitivo e tecnológico. Diante disso, esse mesmo autor fez uma análise do grau de satisfação dos professores dos Institutos Federais (IF) com a QVT, diante dos impactos de sua expansão no Brasil. A pesquisa mista, exploratória, descritiva, utilizando como instrumento o Protocolo Biopsicossocial e Organizacional (BPSO-96), de Limongi-França. Ele constatou que o social apresentou o menor índice de satisfação, enquanto o psicológico obteve maior satisfação. A pesquisa demonstrou a necessidade de alinhamento quanto à política de gestão de benefícios, apoio familiar e comunitário no grupo pesquisado, revelando-se, também, comprometimento e coleguismo entre os professores o que reflete positivamente na qualidade da relação ensinoaprendizagem no âmbito da (LIMONGI-FRANÇA et al, 2013).

A pesquisa realizada por Ferreira (2009) também relaciona a QVT em órgãos públicos brasileiros. O autor realizou análise documental e entrevista semiestruturada com 10 órgãos públicos federais. Os resultados mostram que as práticas de QVT se caracterizam por nítido descompasso entre problemas existentes e atividades realizadas, com uma abordagem de QVT de viés assistencialista, que encontra no trabalhador a variável de ajuste. Estes dados 
pesquisados por Ferreira (2009) fornecem importantes elementos para a construção de outros trabalhos que visem uma abordagem de QVT de natureza preventiva.

Um aspecto preponderante quando se fala em QVT é o estresse gerado pelo trabalho e pelas atividades gerais, uma vez que, preocupações com a saúde e situação econômica, podem levar a estágios depressivos. Normalmente, o estresse é definido como uma reação fisiológica ou psicológica do indivíduo a uma determinada exigência (WEINECK, 2003). Para isso defende-se a eficiência da qualidade de vida como reversão e prevenção aos casos depressivos. $O$ tratamento psicológico é indicado como uma das melhores alternativas para tirar as pessoas do estado de depressão (CARVALHAL, 2008). "O poder de cura está no paciente. É este quem se dispõe a decidir sobre sua condição psicológica e reformular sua conduta de vida" (JOÃO apud GOULING, 1987, p.116).

Sacomano (2010) trata da interface entre direito, ética, sustentabilidade e qualidade, tendo como foco principal a responsabilidade social, dentro das organizações e, em um cenário maior, a qualidade de vida dos cidadãos. Para tanto, além do embasamento teórico, foram realizadas pesquisas bibliográficas e de campo com a finalidade de constatar a influência dos fatores acima mencionados na qualidade dos produtos/serviços, e, por consequência, a relação com a qualidade de vida da sociedade. Temas como sustentabilidade, Direito do Consumidor, Ética e Responsabilidade Social estão ganhando importância cada vez maior dentro da sociedade, fato que influencia diretamente na relação produção - mercado.

Tais conceitos estão intrinsecamente ligados entre si, tanto que a própria norma NBR 16001 da Associação Brasileira de Normas Técnicas (ABNT), que estabelece os requisitos mínimos relativos a um sistema da gestão da responsabilidade social traz, como primeiro objetivo, a implementação de uma política que leve em conta os requisitos legais, seus compromissos éticos e sua preocupação com a promoção da cidadania, a promoção do desenvolvimento sustentável e a transparência das suas atividades. Esses conceitos também estão extensamente ligados com a Engenharia de Produção, e certamente levarão a reflexões e mudanças nas práticas organizacionais e nas atividades de chão de fábrica de produção. Assim, as organizações devem estrategicamente considerar tais fatores no âmbito de sua produção, de modo a competir no mercado e, sobretudo, satisfazer o consumidor, atualmente mais exigente com relação aos seus direitos sobre produtos e serviços (SACOMANO, 2010).

Em síntese, a qualidade de vida no trabalho abraça importantes elementos da vida pessoal e do ambiente de trabalho, os quais precisam ser trabalhados de forma individual ou conjuntamente. A seguir foi descrita a proposta de um instrumento para medida da qualidade de vida, o qual foi a base para a coleta de dados deste estudo.

\section{MÉTODO DO ESTUDO}

Este estudo constou de uma pesquisa descritiva com abordagem quantitativa, desenvolvida com os Servidores Técnico-Administrativos em Educação (TAE) do Centro de Artes e Letras (CAL) da Universidade Federal de Santa Maria (UFSM). Segundo Sampieri; Collado e Lucio (2006), em um estudo descritivo seleciona-se uma série de questões medindo e coletando informação sobre cada uma delas, para assim descrever o que se pesquisa. 
Para Hair (2005), os dados quantitativos são mensurações em que números são usados diretamente para representar as propriedades de algo. Como são registrados diretamente com números, os dados estão em uma forma que se presta para a análise estatística. Os dados qualitativos geralmente são coletados utilizando-se algum tipo de entrevista não-estruturada. Representam descrições de coisas sem a atribuição direta de números (HAIR JR, 2005).

Este estudo fez uso de pesquisa survey (BABBIE, 1999), que é um procedimento para coleta de dados primários a partir de indivíduos. Os dados podem variar entre crenças, opiniões, atitudes e estilos de vida, até informações gerais sobre a experiência do indivíduo (HAIR JR, 2005, p. 157).

\subsection{Unidade de análise e sujeitos da pesquisa}

Esta pesquisa foi realizada em uma das subunidades acadêmicas da Instituição, Centro de Artes e Letras (CAL), localizado no prédio 40, que possui 43 Servidores Técnico-Administrativos, alocados em níveis de apoio, intermediário e superior e com cargos administrativos e técnicos de nível de área afim. Participaram da coleta de dados, 42 servidores, constituindo, a população pesquisada. "População é a soma de todos os elementos que compartilham algum conjunto comum de características e que compreende o universo para o problema de pesquisa de marketing" (MALHOTRA, 2006, p.320).

\subsection{Instrumento e forma de coleta de dados}

O instrumento de coleta de dados foi composto por dois blocos de questões. O primeiro tem a finalidade de identificar o perfil dos pesquisados: (i) Idade; (ii) Setor onde atua; (iii) Tempo de INSTITUIÇÃO; (iv) Ocupação de chefia; (v) Tempo na função de chefia, contendo questões sociodemográficas, além de questões para identificar a atuação ou posição do indivíduo na organização em estudo.

O segundo bloco de questões tomou base no questionário desenvolvido e validado por Constantino (2007), o qual contempla o constructo Bem-estar no Trabalho (QVT).

Tabela 1 - Indicadores de QVT

\begin{tabular}{|l|l|}
\hline & \multicolumn{1}{|c|}{ 1. Bem-estar no trabalho - QVT } \\
\hline 1 & Atendimento do convênio médico que a INSTITUIÇÃO oferece. \\
\hline 2 & Benefícios oferecidos pela INSTITUIÇÃO (farmácia, creche, cesta básica, previdência privada, etc.). \\
\hline 3 & Qualidade das refeições oferecidas pela INSTITUIÇÃO . \\
\hline 4 & Oportunidade de carreira que a INSTITUIÇÃO oferece. \\
\hline 5 & Imagem da INSTITUIÇÃO junto aos funcionários (ou junto à comunidade). \\
\hline 6 & Oportunidade de treinamento e desenvolvimento profissional que a INSTITUIÇÃO oferece. \\
\hline 7 & Oportunidade de participar de comitês de decisão na INSTITUIÇÃO. \\
\hline 8 & O meu salário é compatível com a minha função e com o mercado. \\
\hline 9 & A INSTITUIÇÃO se preocupa com o ambiente físico e com a segurança no trabalho. \\
\hline 10 & A INSTITUIÇÃO promove o equilíbrio entre a minha vida pessoal e o trabalho. \\
\hline
\end{tabular}




\begin{tabular}{|l|l|}
\hline 11 & A INSTITUIÇÃO se preocupa com o relacionamento interpessoal entre os funcionários e as chefias. \\
\hline 12 & Atendimento do apoio ou assistência psicológica que a INSTITUIÇÃO oferece. \\
\hline
\end{tabular}

Fonte: Elaborado com base em Constantino (2007)

\subsection{Procedimento de análise dos resultados}

O processo de análise foi realizado de acordo com os objetivos propostos, conforme apresentado na Tabela 2 . Incluiu o uso de estatística descritiva simples e análise qualitativa.

Tabela 2 - Procedimentos de análise dos resultados

\begin{tabular}{|l|l|}
\hline \multicolumn{1}{|c|}{ Objetivo } & \multicolumn{1}{|c|}{ Procedimento de análise } \\
\hline $\begin{array}{l}\text { Identificar a autopercepção dos servidores quanto à } \\
\text { qualidade de vida e bem-estar no trabalho; }\end{array}$ & $\begin{array}{l}\text { Estatística descritiva simples com base em } \\
\text { frequências, média, máximo e mínino e } \\
\text { desvio padrão. }\end{array}$ \\
\hline $\begin{array}{l}\text { Analisar as relações da auto percepção da qualidade de vida } \\
\text { e bem-estar no trabalho com as características do perfil } \\
\text { sociodemográfico dos servidores TAE do CAL/INSTITUIÇÃO; }\end{array}$ & Análise de correlação e diferenças de médias \\
\hline $\begin{array}{l}\text { Analisar as relações entre o construto da qualidade de vida e } \\
\text { o bem-estar no trabalho e }\end{array}$ & Análise de correlação e diferenças de médias \\
\hline $\begin{array}{l}\text { Analisar a percepção qualitativa dos pesquisados acerca da } \\
\text { qualidade de vida e do bem-estar no trabalho }\end{array}$ & Análise qualitativa \\
\hline $\begin{array}{l}\text { Propor atividades com abordagens multidisciplinares tendo } \\
\text { em vista a melhoria da Qualidade de Vida e o bem-estar no } \\
\text { trabalho dos servidores. }\end{array}$ & Interpretação qualitativa dos resultados \\
\hline
\end{tabular}

\section{RESULTADOS}

Os resultados mostram que $52,4 \%$ dos entrevistados são do sexo masculino e $47,6 \%$ do sexo feminino. Em torno de $70 \%$ do grupo pesquisado possui até 50 anos, denotando que se trata de um grupo com maturidade. Quanto ao estado civil, 47, 6 \% são casados, $28,6 \%$ solteiros e 23,8 apresentam outros casos. A escolaridade do grupo é elevada, uma vez que $81 \%$ possuem curso superior, 57,2 \% tem pós-graduação em nível de especialização e 26,2 \% tem mestrado. A qualificação é um traço marcante no grupo pesquisado. A renda familiar do grupo pesquisado pode se dizer que é acima da realidade do mercado, já que 52,4 \% possui renda familiar de 4 a 7 salários mínimos e 38,1\% acima de 8 salários.

Quanto ao tempo de serviço, chama atenção o fato de que 33,3 \% possuem menos de 5 anos e 35,7 \% mais de 20 anos. Este resultado remete a duas situações vivenciadas pela Instituição como um todo: a renovação do quadro funcional por ocasião do REUNI (Programa de Renovação das Universidades Federais) e o tempo de existência da instituição que atingiu 54 anos em 2014. Se por um lado existem muitas pessoas em situação de aposentadoria, por outro o quadro se renova pela adesão da Instituição aos programas de governo. Os resultados evidenciaram que se trata de um grupo com alta escolaridade, situação familiar estável e com maturidade em termos de idade. 


\subsection{Bem-estar no trabalho}

Esta seção apresenta os resultados relativos ao construto bem-estar no trabalho. É importante referir que na Tabela 1 foi usada a seguinte indicação: nota 1 (totalmente insatisfeito) e nota $\mathbf{5}$ (totalmente satisfeito) e N/E se não existe a ação.

Tabela 3 - Dimensões do construto bem-estar no trabalho

\begin{tabular}{|c|c|c|c|c|c|c|c|c|c|}
\hline \multirow{2}{*}{\multicolumn{2}{|c|}{ Indicador }} & \multicolumn{8}{|c|}{$\%$} \\
\hline & & NR & 1 & 2 & 3 & 4 & 5 & N/E & $T$ \\
\hline 1 & $\begin{array}{l}\text { Atendimento do convênio } \\
\text { médico que a INSTITUIÇÃO } \\
\text { oferece }\end{array}$ & 9,5 & 16,7 & 9,5 & 23,8 & 14,3 & 9,5 & 16,7 & 100 \\
\hline 2 & 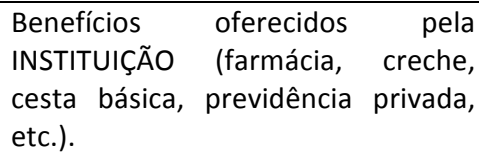 & 7,1 & 7,1 & 19,0 & 23,8 & 21,4 & 2,4 & 19,0 & 100 \\
\hline 3 & $\begin{array}{l}\text { Qualidade das refeições } \\
\text { oferecidas pela INSTITUIÇÃO. }\end{array}$ & 4,8 & 2,4 & 4,8 & 14,3 & 47,6 & 21,4 & 4,8 & 100 \\
\hline 4 & $\begin{array}{l}\text { Oportunidade de carreira que a } \\
\text { INSTITUIÇÃO oferece. }\end{array}$ & 2,4 & 9,5 & 9,5 & 28,6 & 31,0 & 16,7 & 2,4 & 100 \\
\hline 5 & $\begin{array}{l}\text { Imagem da INSTITUIÇÃO junto } \\
\text { aos funcionários (ou junto à } \\
\text { comunidade). }\end{array}$ & 2,4 & - & 2,4 & 28,6 & 47,6 & 14,3 & 4,8 & 100 \\
\hline 6 & $\begin{array}{l}\text { Oportunidade de treinamento e } \\
\text { desenvolvimento profissional } \\
\text { que a INSTITUIÇÃO oferece. }\end{array}$ & - & 2,4 & 9,5 & 19,0 & 45,2 & 21,4 & 2,4 & 100 \\
\hline 7 & $\begin{array}{l}\text { Oportunidade de participar de } \\
\text { comitês de decisão na } \\
\text { INSTITUIÇÃO. }\end{array}$ & - & 2,4 & 21,4 & 35,7 & 28,6 & 7,1 & 4,8 & 100 \\
\hline 8 & $\begin{array}{l}\text { O meu salário é compatível com } \\
\text { a minha função e com o } \\
\text { mercado. }\end{array}$ & - & - & 9,5 & 42,9 & 31,0 & 16,7 & - & 100 \\
\hline 9 & $\begin{array}{l}\text { A INSTITUIÇÃO se preocupa com } \\
\text { o ambiente físico e com a } \\
\text { segurança no trabalho. }\end{array}$ & 2,4 & 7,1 & 19,0 & 42,9 & 21,4 & 7,1 & - & 100 \\
\hline $\begin{array}{l}1 \\
0\end{array}$ & $\begin{array}{l}\text { A INSTITUIÇÃO promove o } \\
\text { equilíbrio entre a minha vida } \\
\text { pessoal e o trabalho. }\end{array}$ & - & 11,9 & 28,6 & 35,7 & 16,7 & 7,1 & - & 100 \\
\hline $\begin{array}{l}1 \\
1\end{array}$ & $\begin{array}{l}\text { A INSTITUIÇÃO se preocupa com o } \\
\text { relacionamento interpessoal entre } \\
\text { os funcionários e as chefias. }\end{array}$ & - & 7,1 & 26,2 & 33,3 & 21,4 & 11,9 & - & 100 \\
\hline $\begin{array}{l}1 \\
2\end{array}$ & $\begin{array}{l}\text { Atendimento do apoio ou } \\
\text { assistência psicológica que a } \\
\text { INSTITUIÇÃO oferece. }\end{array}$ & 9,5 & 4,8 & 16,7 & 42,9 & 11,9 & 9,5 & 4,8 & 100 \\
\hline
\end{tabular}


No construto Bem-estar no Trabalho (QVT), os indicadores de atendimento do convênio médico e os benefícios oferecidos pela Instituição, obtiveram o maior percentual de resposta concentrou-se no nível mediano da escala $(23,8 \%)$. A qualidade das refeições oferecidas pela Instituição chega a quase a metade das respostas no nível 4 da escala (47,6\%).

$\mathrm{O}$ indicador relativo à oportunidade de carreira que Instituição oferece apresentou maior percentual de resposta no nível 4 de satisfação $(31,0 \%)$. Quanto à imagem da Instituição quase a metade $(47,6 \%)$ apresentaram sua satisfação no nível 4 da escala. No indicador oportunidade de treinamento e desenvolvimento profissional, 45,2\% demonstraram satisfação no nível 4 . 0 indicador relativo à oportunidade de participar de comitês de decisão apresentou maior percentual de resposta no nível mediano da escala $(35,7 \%)$.

Quanto ao salário, os respondentes, demonstram uma média de satisfação mais elevada, concentrando-se nos níveis mais altos da escala com o maior percentual de respostas no nível 3 (42,9\%). O indicador de preocupação com o ambiente físico e com a segurança no trabalho apresentou o maior percentual de resposta no nível 3 (42,9\%). Assim como o entre a vida pessoal e o trabalho manteve uma média com $35,7 \%$ no nível 3 . No indicador a preocupação com o relacionamento interpessoal entre os funcionários e as chefias houve uma média de 33,3\% no nível 3. Assim como quanto ao atendimento do apoio ou assistência psicológica, quase a metade concentrou-se no nível 3 com 42,9\%.

Em síntese, pode-se depreender dos resultados que os entrevistados apresentaram níveis razoáveis de satisfação com os indicadores de bem-estar no trabalho, neste estudo representando a dimensão da QVT. A QVT compromete-se com as condições de vida no trabalho, que inclui aspectos de bem-estar, garantia da saúde e segurança física, mental e social e capacitação para realizar tarefas com segurança (LIMONGI-FRANÇA e RODRIGUES, 2013). De acordo com o referencial teórico, apresenta ligação com a necessidade de salários equânimes, segurança no emprego, fatores motivacionais, realização e a participação nas decisões de seu próprio trabalho, são pontos centrais para estudos de QVT.

\subsection{Percepções qualitativas sobre bem-estar no trabalho}

O estudo quantitativo foi complementado por dois questionamentos abertos (- Você tem algum comentário sobre o tema? - Você tem alguma sugestão sobre o que poderá ser feito pela Instituição para melhorar a sua Qualidade de Vida no Trabalho?), os quais foram analisados qualitativamente e acrescentaram elementos para as propostas de melhoria apresentadas na seção seguinte. Os resultados do primeiro questionamento estão apresentados na Tabela 4.

Tabela 4 - Comentários sobre o tema da pesquisa

\begin{tabular}{|l|l|}
\hline Pesquisado & Resposta \\
\hline E1 & $\begin{array}{l}\text { "Viabilizar vias alternativas de acesso a INSTITUIÇÃO além da Av. Roraima, ou negociar com a } \\
\text { ATU, para verificar a possibilidade de linhas diretas até à INSTITUIÇÃO, como havia na década } \\
\text { de 80, em que a EXCAL tinha alguns horários em que ela apanhava passageiros até o } \\
\text { Corinthians e depois só havia paradas a partir da Av. Roraima, a fim de diminuir o stress com o } \\
\text { trânsito". }\end{array}$ \\
\hline E2 & "Muito bem escolhido". \\
\hline E3 & "Com esse controle de ponto nossa disponibilidade para resolver problemas pessoais fica \\
\hline
\end{tabular}




\begin{tabular}{|l|l|}
\hline E4 & muito estressante. Ideal trabalharmos num turno, e no outro resolver os problemas pessoais". \\
\hline E5 & $\begin{array}{l}\text { "A minha qualidade de vida é satisfatória porque eu tenho prazer em trabalhar e } \\
\text { complemento a renda com outras atividades, mas tenho pouco descanso e nenhum momento } \\
\text { de lazer dentro da instituição, temos excesso de trabalho". }\end{array}$ \\
\hline E6 & $\begin{array}{l}\text { "Qualidade na empresa de ônibus". } \\
\text { melhorar". }\end{array}$ \\
\hline E7 & $\begin{array}{l}\text { "Trabalhamos longe do prédio da direção do centro, o que dificulta nosso trabalho e } \\
\text { integração com os demais colegas e participação de assuntos que dizem respeito ao nosso } \\
\text { trabalho e nossa canseira profissional". }\end{array}$ \\
\hline E8 & $\begin{array}{l}\text { "Buscar a humanização e valorização das pessoas na Instituição proporcionará um melhor } \\
\text { desenvolvimento pessoal e profissional dos servidores". }\end{array}$ \\
\hline E9 & $\begin{array}{l}\text { "A qualidade de vida de cada um tem muito a ver com os seus próprios hábitos pessoais que } \\
\text { devem ser saudáveis". }\end{array}$ \\
\hline E10 & $\begin{array}{l}\text { "Com relação à Qualidade de Vida: é algo importante, mas não primordial! Muitas vezes é } \\
\text { necessário sacrificar algo da nossa qualidade de vida por um bem maior". }\end{array}$ \\
\hline E11 & $\begin{array}{l}\text { "Minha filosofia de vida é oriental, gosto de preservações, não gosto de expor socialmente } \\
\text { minha conduta". }\end{array}$ \\
\hline
\end{tabular}

A Tabela 5 apresenta as sugestões dos pesquisados para a Instituição para melhorar o bem-estar no trabalho (QVT). É importante destacar que os resultados apresentados na Tabela 4, anteriormente e a seguir na Tabela 5, foram considerados os principais e que evidenciam as principais evidências.

Tabela 5 - Síntese das sugestões sobre QVT

\begin{tabular}{|c|c|}
\hline Pesquisado & Sugestão \\
\hline E1 & $\begin{array}{l}\text { "Criar espaços de convívio por Centro para os servidores, uma vez que a maioria deles } \\
\text { permanece na instituição durante o intervalo de almoço, devido ao tempo que se perde no } \\
\text { trânsito, que não permite mais que os servidores se desloquem de suas casas até as suas } \\
\text { residências no intervalo de almoço". }\end{array}$ \\
\hline E2 & "Redução da jornada para 6 horas diárias". \\
\hline E3 & $\begin{array}{l}\text { "Que as chefias e os Servidores sigam as normas e padrões de segurança e qualidade de } \\
\text { vida". }\end{array}$ \\
\hline E4 & "Retirada do ponto eletrônico". \\
\hline E5 & "Ginástica laboral dentro do ambiente de trabalho". \\
\hline E6 & "Ginástica laboral". \\
\hline E7 & "Construção de um local recreativo para os TAES". \\
\hline E8 & "Palestras motivacionais são muito bem vindas". \\
\hline E9 & $\begin{array}{l}\text { "Um plano de carreira decente, que valorize o esforço e a dedicação de quem seja } \\
\text { merecedor". }\end{array}$ \\
\hline E10 & $\begin{array}{l}\text { "Transporte coletivo um caos. Os ônibus deveriam sair um atrás de outro e não nós ficarmos } \\
\text { ali parados esperando por eles } 7 \text { ônibus parados e turmas enormes esperando a boa }\end{array}$ \\
\hline
\end{tabular}




\begin{tabular}{|c|c|}
\hline & vontade deles de sair e rirem das pessoas". \\
\hline E11 & $\begin{array}{l}\text { "Jornada de trabalho de } 30 \text { horas semanais nos daria maior qualidade de vida e mais tempo } \\
\text { para qualificação". }\end{array}$ \\
\hline E12 & $\begin{array}{l}\text { "Atividade física/recreativa com alongamento e descontração no início das atividades } \\
\text { laborais". }\end{array}$ \\
\hline E13 & "Diminuir a jornada de trabalho para 6 h diárias". \\
\hline E14 & $\begin{array}{l}\text { "Unificar o plano de assistência médica hospitalar, ampliar o atendimento psicológico com } \\
\text { mais profissionais e a inserção destes ao/ao (s) ambiente (s) organizacional (is) da } \\
\text { INSTITUIÇÃO e implementar ações proativa no que tange as relações interpessoais } \\
\text { institucional". }\end{array}$ \\
\hline \multirow[t]{2}{*}{ E15 } & $\begin{array}{l}\text { "Existe uma disparidade enorme entre os TAES e docentes, começando pelo ponto } \\
\text { eletrônico, o que é obrigatório só para o seguimento dos TAES, quando alguns docentes não } \\
\text { aparecem no departamento quase nunca, nem mesmo quando são chamados. Alguns ficam } \\
\text { mais de seis meses sem entrar nas suas salas, onde são alocados, além do espaço físico, } \\
\text { materiais permanentes de ótima qualidade e que não são usados. Penso que essa diferença } \\
\text { de tratamento tem que ser ajustada". }\end{array}$ \\
\hline & $\begin{array}{l}\text { "A Instituição deveria valorizar mais os servidores técnico-administrativos, pois a cada ano } \\
\text { que passa esses estão se qualificando cada vez mais o que possibilita que assumam cargos } \\
\text { de maior relevância nos setores". }\end{array}$ \\
\hline E16 & $\begin{array}{l}\text { "Valorizar mais a PRÁXIS (experiência profissional + formação acadêmica) de trabalho dos } \\
\text { seus servidores (docentes e técnicos)". }\end{array}$ \\
\hline E17 & $\begin{array}{l}\text { "Em meu caso particular, necessito ter mais informações sobre os convênios de saúde, } \\
\text { farmácia, etc... não sei como funcionam estas ciosas com relação aos convênios dos } \\
\text { funcionários". }\end{array}$ \\
\hline E18 & $\begin{array}{l}\text { "Certamente, a redução da carga horária para } 30 \text { horas auxiliaria a ter qualidade de vida, } \\
\text { pois nossa vida não se resume apenas ao trabalho duro e nem a estar cumprindo horas } \\
\text { controlados por ponto eletrônico. O importante é cumprir bem suas tarefas no Setor de } \\
\text { Trabalho, mas sem o massacre da carga horária atual". }\end{array}$ \\
\hline E19 & $\begin{array}{l}\text { "Bom, acho que poderia reduzir o horário de trabalho, mas até lá seria bem prazeroso ter } \\
\text { um ambiente mais higiênico e organizado". }\end{array}$ \\
\hline E20 & $\begin{array}{l}\text { "Estudos descritivos sobre a jornada de trabalho de oito horas e o impacto do equilíbrio } \\
\text { emocional, bem estar (pessoal e profissional) e desempenho organizacional, diante das } \\
\text { atuais condições de transporte público oferecido aos servidores". }\end{array}$ \\
\hline
\end{tabular}

As sugestões incluem questões relacionadas aos aspectos técnicos da gestão de pessoas, tais como: jornada de trabalho, ponto eletrônico, carreira e também questões comportamentais como valorização dos servidores, relações interpessoais, dentre outras.

\subsection{Abordagens multidisciplinares propostas}

As abordagens multidisciplinares propostas decorrem dos resultados evidenciados pela pesquisa e procuram potencializar algumas dimensões com resultados favoráveis indicados pelo grupo pesquisado assim como mudar hábitos ou comportamentos menos favoráveis apontados pelo grupo.

Considerando que é um grupo que possui grande qualificação, pois um percentual significativo possui graduação e pós-graduação e tem a conscientização de que devem ter 
hábitos alimentares adequados e praticar atividade física com regularidade, é importante propor ações que promovam a inserção das pessoas em atividades que procurem minimizar o sedentarismo e o comodismo. Assim, foram sugeridas as seguintes ações inseridas em cada um dos construtos e fatores analisados. No construto qualidade de vida, as propostas foram encaminhadas como:

- Hábitos alimentares: devido à agitação da vida atual percebeu-se que está faltando ambiente agradável para alimentação mais tranquila. A sugestão é de que sejam explorados os encontros de confraternização nos horários de almoço entre colegas e também que sejam providenciados mais espaços para refeições no campus nas subunidades;

- Atividade física: a pesquisa evidenciou que há certo comodismo na prática de atividade física, diante disso propõe-se a inserção da ginástica laboral, atividade que deve ocorrer no local e horário de trabalho e ser promovida pela Instituição. A ginástica laboral foi uma das sugestões mais enfatizadas nas questões abertas do questionário;

- Bem-estar pessoal: a pesquisa apontou diferenças entre homens e mulheres quanto ao bem-estar pessoal. Assim, propõe-se a realização de atividades voltadas às mulheres e que tenham como foco a sua autoestima e sentido da vida;

- Lazer e diversão: há conscientização de que o lazer traz prazer e bem-estar, mas evidenciou-se a necessidade de priorizar outras formas de diversão. No ambiente de trabalho esta questão poderia ser estimulada com a criação de um espaço de recreação para os servidores, conforme sugestão de um dos entrevistados;

- Inserção social: Como há um bom relacionamento e satisfação com as pessoas, sugere-se promover mais encontros e atividades sociais com os grupos de amigos. No ambiente de trabalho, esta questão poderia ser estimulada pela realização de atividades de integração e relacionamento interpessoal dos servidores;

- Ocupação principal: os resultados evidenciam que os servidores têm satisfação, mas podem ter sua criatividade estimulada. Devem variar os tipos de atividades, tanto de lazer como de trabalho, ajuda a ter uma maior visão da vida;

- Bem-estar no trabalho: devido à preocupação com a família, fica um distanciamento entre a vida pessoal e o trabalho, portanto deve ter uma maior integração, fazendo com que a família também sinta aproximação com o trabalho, assim como também da família dos colegas. Os convênios de assistência à saúde devem ter uma maior expansão e diversificação; palestras motivacionais; atividades que promovam a motivação dos servidores mais jovens; capacitação dos servidores e gestores sobre segurança no trabalho.

\section{CONSIDERAÇÕES FINAIS}

O estudo atingiu os objetivos propostos. Quanto à análise da auto percepção dos Servidores com relação à Qualidade de Vida e Bem-estar no Trabalho tendo em vista o desenvolvimento de ações de melhoria, foi possível perceber que o Servidor TAE apresenta satisfação com sua qualidade de vida. $O$ fator mais insatisfatório foi relacionado com atividades físicas o que suscitou a sugestão acerca da ginástica laboral. 
A relação da auto percepção da Qualidade de Vida e Bem-estar no Trabalho com as características do perfil sociodemográfico não apresentou resultados expressivos. Apenas o gênero apresentou diferença significativa no fator bem-estar pessoal em favor do sexo masculino. A relação entre o construto da Qualidade de Vida e o Bem-estar no Trabalho verificou-se que quanto melhores os hábitos alimentares, maior a inserção social e a satisfação com a ocupação principal, ou seja, a satisfação com o bem-estar no trabalho (QVT). Também é possível observar que a inserção social é o construto que apresentou maior associação com QVT, seguido dos hábitos alimentares e da ocupação principal.

Quanto à análise da percepção qualitativa dos pesquisados acerca da qualidade de vida e do bem-estar no trabalho verificou-se que é um grupo maduro, consciente da importância do bem-estar pessoal como prioridade em conjunto com uma boa e constante qualificação para o trabalho.

As abordagens multidisciplinares propostas, visando à melhoria da Qualidade de Vida e o bem-estar no trabalho dos servidores incluíram confraternizações e reuniões entre o referido grupo, oportunizando assim uma aproximação maior das pessoas, facilitando com isso um entendimento e como consequência o resultado será satisfatório.

A conscientização foi outro foco abordado, pois sem a percepção do problema não é possível traçar um planejamento eficaz. A partir daí foram pontuados elementos essenciais para melhorar a qualidade de vida e a produtividade no trabalho como: ter hábitos alimentares saudáveis, praticar ginástica laboral, manter uma média adequada de sono e repouso, o bemestar pessoal com uma boa autoestima, praticar mais passeios semanais, continuar com bom relacionamento familiar e social, permanecer com a dedicação e a satisfação no trabalho, dentre outras.

A ordem de cuidado com a QV atribuída pelos respondentes aos construtos analisados foi: "Bem-estar Pessoal, Ocupação Principal, Inserção Social, Sono e Repouso, Lazer e Diversão, Hábitos Alimentares e Atividade Física". A maior média no construto Bem-estar no Trabalho foi para os "Benefícios oferecidos pela Instituição" e "Qualidade das refeições oferecidas" e a menor para "Equilíbrio entre a vida pessoal e o trabalho". O maior desvio-padrão na QV está na "Atividade física"; enquanto, o menor, aos "Hábitos alimentares". No QVT o maior, encontra-se no "Atendimento do convênio médico", ao passo que o menor é: "O meu salário é compatível com a minha função e com o mercado". Na avaliação geral, o resultado da QV está entre os níveis satisfatório e bom.

Novos estudos podem ser desenvolvidos em outras unidades, ampliando a amostra, incluindo mais questões relativas ao trabalho. Por fim, o estudo baseou-se em apenas um grupo da instituição e foi aplicado num período delimitado. Com isso, foram colhidos dados valiosos para análises e considerações futuras que seguramente contribuirão no aperfeiçoamento da qualidade de vida dos servidores no ambiente de trabalho e também na vida pessoal.

\section{REFERÊNCIAS}

ALBUQUERQUE, L.; LIMONGI-FRANÇA, A. C. (1998). As estratégias de recursos humanos e gestão da qualidade de vida no trabalho: o stress e a expansão do conceito de qualidade total. Revista de Administração, São Paulo, v. 33, n. 2, abr/jun. p. 40-51. 
AMORIM, T. G. F. N. (2010). Qualidade de vida no trabalho: preocupação também para servidores públicos? Revista Eletrônica de Ciência Administrativa, v. 9, n. 1, p. 35-48.

BABBIE, E. (1999). Métodos de pesquisa de survey. Belo Horizonte: Ed. UFMG.

CARVALHAL, C. R. (2008). Como lidar com o estresse em gerenciamento de projetos. Rio de Janeiro: Brasport.

CONSTANTINO, M. A. C. (2007). Avaliação da Qualidade de Vida: desenvolvimento e validação de um instrumento, por meio de indicadores biopsicossociais, junto à Comunidade da Universidade de São Paulo - USP. Tese (Doutorado). São Paulo.

FERREIRA, M. C. (2009). Gestão de Qualidade de Vida no Trabalho (QVT) no Serviço Público Federal: O Descompasso entre Problemas e Práticas Gerenciais. Universidade de Brasília. JulSet, Vol. 25 n. 3, pp. 319-327.

HAIR JR, J. F. (2005). Fundamentos de métodos de pesquisa em administração/ Joseph F. Hair Jr., Barry Babin, Arthur H. Money e Philip Samuel; tradução Lene Belon Ribeiro. - Porto Alegre: Bookmen.

JOÃO, M. I. (1987). Depressão: síndrome da dependência psicológica. São Paulo: EPU.

LIMONGI-FRANÇA, A. C. (2012). Qualidade de vida no trabalho - QVT: conceitos e práticas nas empresas da sociedade pós-industrial. 2a ed. São Paulo: Atlas.

LIMONGI FRANÇA, A. C.; RODRIGUES, A. L. (2013). Qualidade de Vida no Trabalho - práticas e conceitos na sociedade pós-industrial. São Paulo: Editora Atlas.

LIMONGI-FRANÇA, A. C. L.; CASTRO, D. S. P; LIMONGI-FRANÇA (2013), R. R; DA SILVA, I. B. (2013). Qualidade de Vida no Trabalho - QVT dos Professores de Ensino Técnico Federal: os fatores biopsicossociais e organizacionais de satisfação. Revista de Administração e Diálogo. Vol 11, n. 03. DOI: 10.15600/1679-5350/rau.v11n2p143-173

MALHOTRA, N. (2006). Pesquisa de marketing: uma orientação aplicada/ Naresh Malhotra; tradução Laura Bocco. - 4. Ed. - Porto Alegre: Bookman.

MARRAS, J. P. (2009). Administração de recursos humanos: do operacional estratégico. 13. ed. São Paulo: Saraiva.

Rossi, A. M., Quick, J. C., \& Perrewé, P. L. (Eds.) (2009). Stress e qualidade de vida no trabalho: o positivo e o negativo. São Paulo, Brazil: Editora Atlas.

SACOMANO, A. R. (2010). Responsabilidade social como elemento para a sustentabilidade, a qualidade de produtos e serviços e a qualidade de vida. Dissertação Universidade Paulista UNIP. São Paulo.

Sampieri, R. H., Collado, C. F., \& Lucio, P. B. (2006). Metodologia de Pesquisa (3rd ed.). Sao Paulo: McGraw-Hill.

WEINECK, J. (2003)Treinamento ideal. 9ed. São Paulo, Manole.

WESTLEY, W. A (1979). Qualidade de Vida no Trabalho: problemas e soluções. São Paulo: Incisa.

WOLECK, A. (2014). O trabalho, a ocupação e o emprego: Uma perspectiva histórica. Instituto Catarinense de Pós-Graduação. 2000. Disponível em: <http://www.posuniasselvi.com.br/artigos/rev01-05.pdf > Acesso em: 22 de novembro de 2014. 